\title{
PENGARUH PENDIDIKAN KEMUHAMMADIYAHAN TERHADAP SIKAP PERILAKU SISWA DI SMA MUHAMMADIYAH BERAU
}

\author{
Mappanyompa, Husnan \\ Dosen Fakultas Agama Islam Universitas Muhammadiyah Mataram \\ Email: Myompakaltim@gmail.com
}

\begin{abstract}
Abstrak
Pengintegrasian pendidikan agama dan pendidikan sekuler yang dilakukan KH. Ahmad Dahlan disaat mayoritas masyarakat muslim menolak berbagai hal yang berbau kolonial merefleksikan kesadaran pentingnya membangun Islam di atas fondasi kemajuan. Oleh karenanya, dalam sejarah perkembangan Muhammadiyah, pendidikan adalah lokomotif kemajuan dan itu sangat relevan dengan konteks dan tuntutan sosiologis bangsa Indonesia. Penelitian ini adalah penelitian kuantitatif. Dalam penelitian ini penulis menggunakan metode survey. Penelitian ini berusaha untuk mendeskripsikan tentang Pengaruh Pendidikan Kemuhammadiyahan terhadap Sikap Perilaku siswa bidang studi Pendidikan Kemuhammadiyahan di SMA Muhammadiyah Berau. Dari penelitian ini diperoleh: Pertama: Dalam segala aspek-aspeknya bahwa pengaruh Pendidikan kemuhamadiyahan mempunyai pengaruh yang cukup (Cukup Berpengaruh) terhadap Sikap Perilaku Siswa di SMA Muhamadiyah Berau. Kedua: Dari hasil analisis dan dilaporkan secara deskriptif yang menampilkan hasil dalam dalam bentuk verbal kemudian dipersentasekan dengan menggunakan rumus, maka, hasil penelitian menunjukkan bahwa pengaruh Pendidikan Kemuhammadiyahan terhadap Sikap Perilaku Siswa SMA Muhammadiyah Berau adalah cukup berpengaruh. Hal ini dibuktikan dengan hasil penelitian yang kemudian di tabulasi dengan menggunakan peresentasi di interpretasikan dengan menggunakan skala interpretasi yang ditetapkan, maka diketahui angka 2,210 termasuk kedalam kategori cukup baik. Dengan demikian maka dapat disimpulkan bahwa pengaruh Pendidikan Kemuhammadiyahan terhadap sikap prilaku Siswa khususnya kelas $X$ dan XI yang diperoleh yakni dapat di kategorikan Cukup Berpengaruh.
\end{abstract}

Kata kunci: Pengaruh Pendidikan Kemuhammadiyahan Terhadap Sikap

\begin{tabular}{|c|c|c|c|} 
Jurnal & Volume & Nomor & Halaman \\
Ibtida'iy & 04 & 1 & $1-97$
\end{tabular}

Mataram
April 2019

$\operatorname{ISSN}$
$2501-504 \mathrm{X}$ 


\section{A. PENDAHULUAN}

Hai orang-orang yang beriman, apabila dikatakan kepadamu oleh siapa pun: "Berlapang-lapanglah yakni berupayalah dengan sungguh-sungguh walau dengan memaksakan diri untuk memberi tempat orang lain dalam majlis-majlis yakni satu tempat, baik tempat duduk maupun bukan untuk duduk. Apabila diminta kepadamu agar melakukan itu maka lapangkanlah tempat itu untuk orang lain dengan suka rela. Jika kamu melakukan hal tersebut, niscaya Allah akan melapangkan segala sesuatu buat kamu dalam hidup ini. Dan apabila dikatakan: Berdirilah kamu ketempat yang lain, atau untuk duduk ditempatmu buat orang yang lebih wajar, atau bangkitlah untuk melakukan sesuatu seperti untuk shalat dan berjihad, maka berdiri dan bangkit-lah, Allah akan meninggikan orang-orang yang beriman diantara kamu wahai yang memperkenankan tuntunan ini dan orang-orang yang diberi ilmu pengetahuan beberapa derajat kemuliaan didunia dan akhirat dan Allah terhadap apa yang kamu kerjakan sekarang dan masa datang Maha mengetahu.

Kualitas hidup sangat ditentukan oleh faktor Pendidikan. Peran Pendidikan sangat penting untuk menciptakan kehidupan yang cerdas, damai terbuka dan demokratis. Perwujudan masyarakat berkualitas menjadi tanggung jawab Pendidikan, terutama dalam persiapan peserta didik menjadi subjek yang makin berperan menampilkan dirinya yang tangguh, kreatif mandiri dan profesional pada bidangnya masing-masing. Hal tersebut diperlukan, terutama untuk mengantisipasi era globalisasi pasar bebas. Sesuai dengan:

"Undang-undang Sistem Pendidikan Nasional No.20 tahun 2003 menyatakan bahwa Pendidikan Nasional bertujuan untuk mengembangkan potensi peserta didik agar menjadi manusia beriman dan bertaqwa kepada Tuhan Yang Maha Esa, berakhlak mulia, sehat, berilmu, cakap, kreatif, mandiri dan menjadi warga negara yang demokratis serta bertanggung jawab".

Sejak awal keberadaannya, Muhammadiyah telah memilih pendidikan dan pelayanan sosial sebagai strategi gerakan dalam mewujudkan masyarakat Islam yang sebenar-benarnya. Pengintegrasian pendidikan agama dan pendidikan sekuler yang dilakukan KH. Ahmad Dahlan disaat mayoritas masyarakat muslim menolak berbagai hal yang berbau kolonial merefleksikan kesadaran pentingnya membangun Islam di atas fondasi kemajuan. Oleh karenanya, dalam sejarah 
perkembangan Muhammadiyah, pendidikan adalah lokomotif kemajuan dan itu sangat relevan dengan konteks dan tuntutan sosiologis bangsa Indonesia.

Oleh karenanya, setiap peserta didik, Siswa dan siswi maupun maha siswa dan mahasiswi, di semua lingkungan insitusi Muhammadiyah di wajibkan mengikutinya, yakni pengajaran $\mathrm{Al}$ Islam dan Kemuhammadiyahan (AIK) kecuali bagi peserta didik/mahasiswa non Muslim. Cukup banyak siswa dan mahasiswi Non Muslim yang menuntut ilmu di institusi-insitusi Muhammadiyah dan mereka hanya diharuskan mengikuti pelajaran/ perkuliahan Kemuhammadiyahan dan Bahasa Arab saja.

Bagi Muhammadiyah sendiri, muatan Pendidikan $\mathrm{Al}$ Islam dan Kemuhammadiyahan bersifat dinamis, terbuka, dan praksis sehingga memiliki peran dan relevansi bagi pengembangan masyarakatnya. Setidaknya ada dua poin penting yang dapat disimpulkan, yakni :

Pertama, bahwa berislam yang mantap (afdhal/utama) tidak hanya semata dibangun oleh pemahaman keagamaan yang benar namun juga harus disertai kemampuannya untuk menjawab berbagai permasalahan sosial-empirik (praksis).

Kedua, kedalaman wawasan dan pengetahuan yang terkandung dalam sumber-sumber keagamaan, dalam konteks ini Al Islam dan Kemuhammadiyahan, hanya mungkin diperoleh melalui penerapan pendekatan yang multi perspektif dan lintas disiplin. Contohnya, Pengembangan Sistem Pendidikan Muhammadiyah yang diusulkan Majelis Dikdasmen Pimpinan Pusat Muhammadiyah mencerminkan semangat tersebut, diantaranya dengan memasukan Pendidikan demokrasi dalam rumusan standar isi Al Islam.

Namun pada kenyataannya, secara perlahan Pendidikan Al Islam dan Kemuhammadiyahan mulai kehilangan vitalitasnya sebagai inti dari Pendidikan di Muhammadiyah di tengah menjamurnya lembaga-lembaga Pendidikan lain yang berkembang secara kompetitif. Di antara faktor penyebabnya adalah masalah spesifikasi dan kompetensi pendidik, minimnya pembinaan Guru, keterbatasan akses bacaan, dan kondisi buku teks Al Islam dan Kemuhammadiyahan yang jauh dari memadai, baik dari segi keterbaruan muatan (up to date) maupun ketersediaan (distribusi), dan lemahnya mengembangkan Kurikulum Tingkat 
Satuan Pendidikan (KTSP). Diperkenalkannya Kurikulum Tingkat Satuan Pendidikan oleh Pemerintah telah menimbulkan "permasalahan" baru pada tingkat satuan Pendidikan (sekolah).

Pada prinsipnya hanya memuat standar-standar yang bersifat nasional. Dengan demikian isi kurikulum diciptakan dan disusun oleh pendidik pada tingkat satuan tingkat pendidikan. Memungkinkan pengembangan kurikulum diletakkan pada posisi yang paling dekat dengan proses pembelajaran, yaitu satuan pendidikan dan dikembangkan sesuai dengan kondisi satuan pendidikan, potensi dan karakteristik daerah, serta sosial budaya masyarakat setempat dan peserta didik. Sehingga pihak Majelis Dikdasmen PP Muhammadiyah telah menerapkan kebijakan desentralisasi pendidikan yang memberikan kewenangan pada setiap majelis Dikdasmen wilayah untuk menjabarkannya pada tingkat operasional, namun "langkah maju" ini tidak berjalan secara baik. Keterbatasan sumber daya manusia dan sulitnya pendanaan untuk proses penyusunan sekaligus penerbitan buku-buku teks pelajaran Al Islam dan Kemuhammadiyahan merupakan kendala umum yang menimpa hampir semua wilayah, utamanya yang berada di luar Jawa.

Padahal peran buku teks pelajaran sangat penting dalam proses belajarmengajar. Berbagai hasil studi menunjukkan bahwa buku teks pelajaran berkontribusi secara signifikan terhadap prestasi belajar peserta didik. Memang disadari bahwa pengembangan buku teks pelajaran, misalnya sebagaimana yang diperuntukkan bagi sekolah-sekolah umum bukanlah sesuatu yang mudah dan murah karena adanya berbagai kepentingan politik, ekonomi, pedagogi, dan ideologi walaupun tidak dibahas secara mendalam di dalam penelitian ini, namun hal tersebut sangat mungkin terjadi dalam penulisan dan penerbitan buku-buku teks pelajaran Al Islam dan Kemuhamadiyahan.

Standarisasi isi kurikulum, kualifikasi pengetahuan tenaga pendidik serta pengembangan metode pengajaran Al-Islam dan Kemuhammadiyahan merupakan masalah krusial yang harus dibenahi dalam proses pengembangan Sistem Pendidikan Muhammadiyah sebagaimana telah disadari Majelis Dikdasmen PP Muhammadiyah. Untuk itulah penulis tertarik untuk membahasnya dalam suatu penelitian ilmiah yang berjudul "Pengaruh Pendidikan Kemuhammadiyahan Terhadap Sikap Perilaku Siswa Di SMA Muhammadiyah Berau” 


\section{Rumusan Masalah}

Berdasarkan latar belakang masalah diatas, maka rumusan masalah yang dibahas adalah sebagai berikut:

1. Apakah terdapat pengaruh Pendidikan Kemuhammadiyahan terhadap sikap perilaku siswa di SMA Muhammadiyah Berau.

2. Sejauh mana pengaruh Pendidikan Kemuhammadiyahan terhadap sikap perilaku siswa di SMA Muhammadiyah Berau.

\section{Alasan Memilih Judul}

1. Pendidikan Kemuhammadiyahan merupakan bidang study terpenting dalam mengubah sikap perilaku siswa dalam meneladani Rasululla SAW, terutama dalam keseharian ketika berinteraksi dengan sesama teman disekolah dan juga dilingkungan masyarakat diluar sekolah .

2. Bahwa dengan mempelajari Pendidikan Kemuhammadiyahan mampu memperaktekkan nilai-nilai ibadah dalam sikap perilaku sehari-harnya.

\section{Penegasan Judul}

Untuk menghindari kesalah fahaman dalam mengartikan judul di atas, maka penulis perlu memberikan penegasan dari masalah tersebut diantaranya:

1. Pendidikan adalah: Usaha sadar dan terencana untuk mewujudkan suasana belajar dan proses pembelajaran agar peserta didik secara aktif mengembangkan potensi dirinya untuk memiliki kekuatan spiritual keagamaan, pengendalian diri, kepribadian, kecerdasan, akhlak mulia, serta keterampilan yang diperlukan dirinya, masyarakat, bangsa dan negara.

2. Kemuhammadiyahan: Secara bahasa berarti "pengikut Nabi Muhammad". Penggunaan kata "Muhammadiyah" dimaksudkan untuk menisbahkan (menghubungkan) dengan ajaran dan jejak perjuangan Nabi Muhammad.

3. Sikap Perilaku: adalah tingkahlaku yang lahir dari emosi. Ia adalah kumpulan perangai yang ditunjukan oleh seseorang terhadap orang lain. Ia merupakan komponen emosi dan salah satu perkara yang sukar dipahami dan diurus.

Dalam penelitain ini penulis menfokuskan pembahasan hanya pada pengaruh Pendidikan Kemuhammadiyahan terhadap Sikap Perilaku Siswa SMA Muhammadiyah Berau khususnya bidang studi Kemuhammadiyahan. 


\section{Tujuan Penelitian}

Berdasarkan rumusan masalah maka penelitian ini bertujuan:

1. Untuk mengetahui apakah terdapat pengaruh Pendidikan Kemuhammadiyahan terhadap Sikap Perilaku Siswa di SMA Muhammadiyah Berau.

2. Untuk mengetahui sejauh mana pengaruh Pendidikan Kemuhammadiyahan terhadap Sikap Perilaku Siswa di SMA Muhammadiyah Berau

\section{B. METODE PENELITIAN}

Jenis penelitian ini adalah penelitian kuantitatif. Dalam penelitian ini penulis menggunakan metode survey. Penelitian ini berusaha untuk mendeskripsikan tentang Pengaruh Pendidikan Kemuhammadiyahan terhadap Sikap Perilaku siswa bidang studi Pendidikan Kemuhammadiyahan di SMA Muhammadiyah Berau dan peran guru Kemuhammadiyahan terhadap sikap prilaku siswa di SMA Muhammadiyah. Hasil survey ditabulasikan dan diolah dalam bentuk tabel, dianalisis dan dilaporkan secara deskriptif yang menampilkan hasil dalam bentuk verbal, kemudian dipersentasikan.

\section{Subyek Dan Obyek Penelitian}

a) Subyek Penelitian

Hal yang menjadi subjek penelitian adalah Pendidikan Kemuhammadiyahan di Sekolah Menengah Atas (SMA) Muhammadiyah Berau.

b) Obyek Penelitian

Hal yang menjadi obyek penelitian ini adalah sikap prilaku Siswa di sekolah menengah atas Muhammadiyah Berau.

\section{Populasi dan Sampel}

a) Populasi

Sesuai dengan judul dan objek penelitian dalam penulisan ini yakni: Pengaruh Pendidikan Kemuhammadiyahan Terhadap Sikap Perilaku Siswa SMA Muhammadiyah Berau, maka yang menjadi populasinya adalah Seluruh Siswa SMA Muhammadiyah Berau kelas X dan XI. Peneliti tidak mengambil sampel dari kelas XII karena pada saat penelitian berlangsung bertepatan dengan Ujian Akhir Nasional (UAN). 
b) Sampel

Sampel dalam penelitaian ini adalah Siswa SMA Muhammadiyah Berau kelas X dan XI. Adapun cara pengambilan respondennya adalah dengan menggunakan tekhnik sampel acak (random sampling) yaitu dengan cara penulis mengambil sampel secara acak masing-masing kelas X 25 orang Siswa dan kelas XI 25 orang Siswa, sehingga sampel keseluruhan berjumlah 50 orang Siswa.

\section{Teknik Pengumpulan Data}

Field Work Reseach, Penulis mengadakan penelitian dengan menggunakan teknik antara lain:

1. Observasi

Observasi kepada semua responden yang telah ditetapkan oleh peneliti dengan cara terjun langsung kelapangan untuk mengamati meningkatkan efektifitas belajar bidang studi Pendidikan Kemuhammadiyah ankelas X dan XI di SMA Muhammadiyah Berau.

2. Wawancara

Penulis melakukan wawancara dengan Guru tentang bagaimana cara pengajaran Pendidikan Kemuhammadiyahan serta hal-hal lain yang berkaitan dengan permasalahan yang diteliti.

3. Dokumentasi

Peneliti mengumpulkan dokumentasi-dokumentasi, laporan dan catatancatatan yang ada hubungannya dengan penelitian.

4. Angket

Penulis menggunakan angket untuk mendapatkan informasi dari Siswa yang berkaitan dengan objek penelitian.

Kemudian untuk menganalisa data yang diperoleh melalui angket, pemberian skor angket menurut skala Likert dengan pernyataan positif, dimana tiap item dibagi kedalam 4 skala:

1. Untuk item dengan jawaban a skor 4

2. Untuk item dengan jawaban $\mathrm{b}$ skor 3

3. Untuk item dengan jawaban c skor 2

4. Untuk item dengan jawaban d skor 1 


\section{PEMBAHASAN}

\section{Penyajia Data}

Dari hasil pengamatan, angket yang telah disebarkan dan nilai afektif Siswa SMA Muhammadiyah kelas X dan XI. Agar lebih jelas hasil jawaban angket yang telah disebarkan pada Siswa SMA Muhammadiyahkelas X dan XI antara Pengaruh Pendidikan Kemuhammadiyahan dan Sikap Perilaku Siswa dipaparkan pada tabel berikut:

Tabel1. Melaksanakan shalat lail disepertiga malam

\begin{tabular}{|c|l|c|c|c|c|}
\hline No. & \multicolumn{1}{|c|}{$\begin{array}{c}\text { Alternatif } \\
\text { Jawaban }\end{array}$} & Interval & Frekuensi & Prosentase & Skor \\
\hline 1. & a. Selalu & 4 & 21 & 26,25 & 84 \\
2. & b. Sering & 3 & 14 & 17,5 & 42 \\
3. & c. Kadang-kadang & 2 & 43 & 53,75 & 86 \\
4. & d. Tidak Pernahh & 1 & 2 & 2,5 & 2 \\
\hline \multicolumn{2}{|r|}{ Jumlah } & 80 & 100 & 214 \\
\hline
\end{tabular}

Tabel diatas dengan jelas menunjukkan bahwa mayoritas anak yang sekolah di SMA Muhammadiyah Tanjung Redeb yang selalu melaksanakan shalat lail disepertiga malam yaitu sebanyak 26,25\% untuk kategori selalu, 17,5\% untuk kategori sering, 53,75\% untuk kategori kadang-kadang, sedangkan jawaban tidak pernah melaksanakan shalat lail disepertiga malam adalah 2,5\%.

Tabel 2. Percaya terhadap mukjizat Rasulullah dan juga para Nabi

\begin{tabular}{|c|l|c|c|c|c|}
\hline No. & Alternatif Jawaban & Interval & Frekuensi & Prosentase & Skor \\
\hline 1. & a. Selalu & 4 & 68 & 85 & 272 \\
2. & b. Sering & 3 & 6 & 7,5 & 18 \\
3. & c. Kadang-kadang & 2 & 6 & 7,5 & 12 \\
4. & d. Tidak Pernahh & 1 & - & - & - \\
\hline \multicolumn{2}{|c|}{ Jumlah } & & 80 & 100 & 302 \\
\hline
\end{tabular}

Tabel diatas dengan jelas menunjukkan bahwa mayoritas anak yang sekolah di SMA Muhammadiyah Tanjung Redeb yang selalu percaya terhadap mukjizat Rasulullah dan juga para Nabi yaitu sebanyak $85 \%$ untuk kategori selalu, 7,5\% untuk kategori sering, 7,5\% untuk kategori kadang-kadang, 
sedangkan jawaban menyatakan tidak pernah Percaya terhadap mukjizat Rasulullah dan juga para Nabi adalah $0 \%$.

Tabel 3. Percaya manusia akan dihisab sesuai dengan amal perbuatannya

\begin{tabular}{|c|l|c|c|c|c|}
\hline No. & Alternatif Jawaban & Interval & Frekuensi & Prosentase & Skor \\
\hline 1. & a. Selalu & 4 & 41 & 51,25 & 164 \\
2. & b. Sering & 3 & 19 & 23.75 & 57 \\
3. & c. Kadang-kadang & 2 & 17 & 21,25 & 34 \\
4. & d. Tidak Pernahh & 1 & 3 & 3,75 & 3 \\
\hline \multicolumn{2}{|c|}{ Jumlah } & 80 & 100 & 258 \\
\hline
\end{tabular}

Tabel diatas dengan jelas menunjukkan bahwa mayoritas anak yang sekolah di SMA Muhammadiyah Tanjung Redeb yang selalu percaya bahwa manusia akan dihisab sesuai dengan amal perbuatannya yaitu sebanyak 51,25\% untuk kategori selalu, 23,75\% untuk kategori sering, 21,25\% untuk kategori kadang-kadang, sedangkan jawaban yang tidak percaya manusia akan dihisab sesuai dengan amal perbuatannya adalah $3,75 \%$.

Tabel 4. Selalu mengingat Allah baik di waktu susah maupun senang

\begin{tabular}{|c|l|c|c|c|c|}
\hline No. & Alternatif Jawaban & Interval & Frekuensi & Prosentase & Skor \\
\hline 1. & a. Selalu & 4 & 6 & 7,5 & 24 \\
2. & b. Sering & 3 & 8 & 10 & 24 \\
3. & c. Kadang-kadang & 2 & 56 & 70 & 112 \\
4. & d. Tidak Pernahh & 1 & 10 & 12,5 & 10 \\
\hline \multicolumn{2}{|c|}{ Jumlah } & 80 & 100 & 170 \\
\hline
\end{tabular}

Tabel diatas dengan jelas menunjukkan bahwa mayoritas anak yang sekolah di SMA Muhammadiyah Tanjung Redeb yang menyatakan selalu mengingat Allah baik di waktu susah maupun senang yaitu 7,5\%untuk kategori selalu, 10\% untuk kategori sering, 70\% untuk kategori kadang-kadang, sedangkan jawaban tidak pernah untuk selalu mengingat Allah baik di waktu susah maupun senang adalah $12,5 \%$. 
Tabel 5. Berbuat baik kepada ibu dan bapak

\begin{tabular}{|c|l|c|c|c|c|}
\hline No. & Alternatif Jawaban & Interval & Frekuensi & Prosentase & Skor \\
\hline 1. & a. Selalu & 4 & 38 & 47,5 & 152 \\
2. & b. Sering & 3 & 19 & 23,75 & 57 \\
3. & c. Kadang-kadang & 2 & 17 & 21.25 & 34 \\
4. & d. Tidak Pernahh & 1 & 6 & 7.5 & 6 \\
\hline \multicolumn{2}{|c|}{ Jumlah } & & 80 & 100 & 249 \\
\hline
\end{tabular}

Tabel diatas dengan jelas menunjukkan bahwa mayoritas anak yang sekolah di SMA Muhammadiyah Tanjung Redeb yang menyatakan selalu berbuat baik kepada ibu dan bapaknya yaitu sebanyak 47,5\% untuk kategori selalu, 23,75\% untuk kategori sering, 21,25\% untuk kategori kadang-kadang, sedangkan jawaban yang menyatakan tidak pernah berbuat baik kepada ibu dan bapak sendiri adalah $7,5 \%$.

Tabel 6. Berbuat baik kepada makhluk ciptaan Allah, termasuk hewan

\begin{tabular}{|c|l|c|c|c|c|}
\hline No. & Alternatif Jawaban & Interval & Frekuensi & Prosentase & Skor \\
\hline 1. & a. Selalu & 4 & 7 & 8,75 & 28 \\
2. & b. Sering & 3 & 12 & 15 & 36 \\
3. & c. Kadang-kadang & 2 & 45 & 56,25 & 90 \\
4. & d. Tidak Pernahh & 1 & 16 & 20 & 16 \\
\hline \multicolumn{2}{|c|}{ Jumlah } & & 80 & 100 & 170 \\
\hline
\end{tabular}

Tabel diatas dengan jelas menunjukkan bahwa mayoritas anak yang sekolah di SMA Muhammadiyah Tanjung Redeb yang menyatakan selalu berbuat baik kepada makhluk ciptaan Allah, termasuk hewan sebanyak 8,75\% untuk kategori selalu, 15\% untuk kategori sering, 56,25\% untuk kategori kadangkadang, sedangkan jawaban yang menyatan tidak pernah berbuat baik kepada makhluk ciptaan Allah, termasuk hewan adalah $20 \%$.

Tabel 7. Selalu melaksanakan puasa pada bulan romadhon

\begin{tabular}{|c|l|c|c|c|c|}
\hline No. & Alternatif Jawaban & Interval & Frekuensi & Prosentase & Skor \\
\hline 1. & a. Selalu & 4 & 42 & 52,5 & 168 \\
2. & b. Sering & 3 & 14 & 17,5 & 42 \\
3. & c. Kadang-kadang & 2 & 22 & 27,5 & 44 \\
4. & d. Tidak Pernahh & 1 & 2 & 2,5 & 2 \\
\hline \multicolumn{2}{|c|}{ Jumlah } & 80 & 100 & 256 \\
\hline
\end{tabular}

Tabel diatas dengan jelas menunjukkan bahwa mayoritas anak yang sekolah di SMA Muhammadiyah Tanjung Redeb yang selalu melaksanakan puasa pada bulan romadhon yaitu sebanyak $52,5 \%$ untuk kategori selalu, $17,5 \%$ untuk 
kategori sering, 27,5\% untuk kategori kadang-kadang, sedangkan jawaban tidak pernah selalu melaksanakan puasa pada bulan romadhon adalah 2,5\%.

Tabel 8. Melaksanakan shalat lima waktu di awal waktu

\begin{tabular}{|c|l|c|c|c|c|}
\hline No. & Alternatif Jawaban & Interval & Frekuensi & Prosentase & Skor \\
\hline 1. & a. Selalu & 4 & 17 & 21,25 & 68 \\
2. & b. Sering & 3 & 17 & 21,25 & 51 \\
3. & c. Kadang-kadang & 2 & 39 & 48,75 & 78 \\
4. & d. Tidak Pernahh & 1 & 7 & 8,75 & 7 \\
\hline \multicolumn{2}{|c|}{ Jumlah } & 80 & 100 & 200 \\
\hline
\end{tabular}

Tabel diatas dengan jelas menunjukkan bahwa mayoritas anak yang sekolah di SMA Muhammadiyah Tanjung Redeb yang selalu melaksanakan shalat lima waktu di awal waktu yaitu sebanyak 21,25\% untuk kategori selalu, 21,25\% untuk kategori sering, 48,75\% untuk kategori kadang-kadang, sedangkan jawaban tidak pernah melaksanakan shalat lima waktu di awal waktu adalah 8,75\%.

Tabel 9. Senang bila dipuji oleh teman

\begin{tabular}{|c|l|c|c|c|c|}
\hline No. & Alternatif Jawaban & Interval & Frekuensi & Prosentase & Skor \\
\hline 1. & a. Selalu & 4 & 54 & 67,5 & 216 \\
2. & b. Sering & 3 & 8 & 10 & 24 \\
3. & c. Kadang-kadang & 2 & 13 & 16,25 & 26 \\
4. & d. Tidak Pernahh & 1 & 5 & 6,25 & 5 \\
\hline \multicolumn{2}{|c|}{ Jumlah } & & 80 & 100 & 271 \\
\hline
\end{tabular}

Tabel diatas dengan jelas menunjukkan bahwa mayoritas anak yang sekolah di SMA Muhammadiyah Tanjung Redeb yang selalu merasa Senang bila dipuji oleh temannya yaitu sebanyak 67,5\%untuk kategori selalu, 10\% untuk kategori sering, 16,25\% untuk kategori kadang-kadang, sedangkan jawaban tidak pernah senang bila dipuji oleh teman adalah $6,25 \%$.

Tabel 10. Membeli barang dan menanyakan asal-usul barang tersebut

\begin{tabular}{|c|l|c|c|c|c|}
\hline No. & Alternatif Jawaban & Interval & Frekuensi & Prosentase & Skor \\
\hline 1. & a. Selalu & 4 & 11 & 13,75 & 44 \\
2. & b. Sering & 3 & 21 & 26,25 & 63 \\
3. & c. Kadang-kadang & 2 & 45 & 56,25 & 90 \\
4. & d. Tidak Pernahh & 1 & 3 & 3,75 & 3 \\
\hline \multicolumn{2}{|c|}{ Jumlah } & & 80 & 100 & 200 \\
\hline
\end{tabular}

Tabel diatas dengan jelas menunjukkan bahwa mayoritas anak yang sekolah di SMA Muhammadiyah Tanjung Redeb yang menyatakan bila membeli barang, selalu menanyakan asal-usul barang tersebut yaitu sebanyak 13,75\% untuk kategori selalu, 26,25\% untuk kategori sering, 56,25\% untuk kategori 
kadang-kadang, sedangkan jawaban yang ketika membeli barang, tidak pernah menanyakan asal-usul barang tersebut adalah 3,75\%.

Data yang diperoleh dari hasil penelitian digambarkan dalam bentuk persentase yaitu:

$$
P=\frac{F}{N} \times 100 \%
$$

Keterangan :

F : Jumlah skor individu (jawaban angket responden)

$\mathrm{N}$ : Jumlah skor total (item angket)

$\mathrm{P}$ : Angka prosentase (Pendidikan kemuhammadiyahan, sikap Perilaku).

Kemudian untuk mngetahui bagaimana pengaruh Pendidikan

Kemuhammadiyahanterhadap Sikap PerilakuSiswa, maka penulis lakukan

denagan dengan uji rata-rata menggunakan rumus:

$$
\begin{aligned}
& \text { Keterangan: } \boldsymbol{M}=\frac{\sum^{X}}{\boldsymbol{N}} \\
& \mathrm{M}=\text { Mean } \\
& \sum^{\mathrm{X}}=\text { Jumlah frekuensi } \\
& \mathrm{N}=\text { Jumlah subyek }
\end{aligned}
$$

$$
\text { Jadi } \frac{44,19}{20}=2,210
$$

Hasil perhitungan yang ada dapat di interpretasikan dengan menggunakan skala interpretasi yang ditetapkan, maka diketahui angka 2,210 termasuk kedalam kategori cukup baik. Dengan demikian maka dapat disimpulkan bahwa pengaruh Pendidikan Kemuhammadiyahanterhadap sikap prilaku Siswa khususnya kelas X dan XI tahun pelajaran 2009/2010 yang diperoleh yakni dapat di kategorikan

\section{Cukup Baik.}

\section{KESIMPULAN}

Muhammadiyah didirikan oleh K.H. Ahmad Dahlan didasari oleh dua faktor, yaitu faktor internal dan faktor eksternal. Faktor internal yaitu faktor yang berkaitan dengan ajaran Islam itu sendiri secara menyeluruh dan faktor eksternal adalah faktor-faktor yang berada di luar Islam. Bagi Muhammadiyah muatan Pendidikan Al Islam dan Kemuhammadiyahan bersifat dinamis, terbuka, dan praksis sehingga memiliki peran dan relevansi bagi pengembangan masyarakatnya, dan dari keseluruhan pembahasan ini dapat disimpulkan sebagai berikut: 
1. Dalam segala aspek-aspeknya bahwa pengaruh Pendidikan kemuhamadiyahan mempunyai pengaruh yang cukup (Cukup Berpengaruh) terhadap Sikap Perilaku Siswa di SMA Muhamadiyah Berau.

2. Dari hasil analisis dan dilaporkan secara deskriptif yang menampilkan hasil dalam dalam bentuk verbal kemudian dipersentasekan dengan menggunakan rumus: $\quad P=\frac{F}{N} \times 100 \%$ a, hasil penelitian menunjukkan bahwa pengaruh Pendidikan Kemuhammadiyahan terhadap Sikap Perilaku Siswa SMA Muhammadiyah Berau adalah cukup berpengaruh.

Hal ini dibuktikan dengan hasil penelitian yang kemudian di tabulasi dengan menggunakan peresentasi di interpretasikan dengan menggunakan skala interpretasi yang ditetapkan, maka diketahui angka 2,210 termasuk kedalam kategori cukup baik. Dengan demikian maka dapat disimpulkan bahwa pengaruh Pendidikan Kemuhammadiyahan terhadap sikap prilaku Siswa khususnya kelas $\mathrm{X}$ dan XI yang diperoleh yakni dapat di kategorikan Cukup Berpengaruh.

\section{E. DAFTAR PUSTAKA}

Ahmad Hatta, MA, Tafsir Qur'an Perkata Jakarta: Magrifah Pustaka 2009.

Ali Syari'ati, Tentang Sosiologi Islam, terj. Saifullah mahyudin, dari judul asli On The Sociologi Of Islam, (Yogyakarta: Amanda 1982).

Amir Hamzah Wirjosukarto, Pembaharuan Pendidikan dan Pengajaran Islam yang Diselenggarakan oleh Pergerakan Muhammadiyah, UP. Ken Mutia, Malang, 1968.

Asjmuni Abdurrahman, H. Moelyadi, Tanya Jawab Agama, Tim Majelis Tarjih Dan Tajdid Pimpinan Pusat Muhammadiyah, (Yogyakarta, November 2003)

Azyumardi Azra, Pendidikan Islam (Tarsito Bandung 2002).

Bambamg Soehendro, Pedoman Model Penilaian Kelas, Kurikulum Tingkat

Satuan Pendidikan TK-SD-SMP-SMK-MI-MTs-MA-MAK, (Jakarta 2007), hal 3

Bambang Abu Abdirrohman, Al Atsary Al Bayaty Artikel: www.muslim.or.id Daoed Yoesoef (1980)

Daoed Yoesoef, Paradigma Pendidikan, Jakarta: 1980

Djamal'uddin Ahmad Al Buni, Pendidikan Kemuhammadiyahan Sekolah

Menengah Umum, (Surbaya:PT. Bina Ilmu 1996)

Mulyasa (2007), Kurikulum Tingkat Satuan Pendidikan: Sebuah Panduan Praktis, Bandung: PT Remaja Rosdakarya.

Fadhil Al-Jamil,Menerabas Krisis Pendidikan Dunia Islam, terj. H.M. Arifin (Jakarta: Golden Terayon Press, 1992). 